\title{
UV Written Channels in Germano Borosilicate Glasses Doped with Sodium
}

\author{
D. Milanese, L. N. Ng, A. Fu and E. R. M. Taylor \\ Optoelectronics Research Centre, University of Southampton, United Kingdom, SO17 1BJ \\ Fax: ++44-1703-593149, Tel: ++44-1703-594530 \\ dm@orc.soton.ac.uk,.1n@orc.soton.ac.uk, af@orc.soton.ac.uk, em@orc.soton.ac.uk \\ C. Contardi, M. Ferraris \\ Politecnico di Torino, C.so Duca degli Abruzzi 24, 10129 Torino, Italy \\ Fax: ++39-011-5644699, Tel: ++39-011-5644687 \\ contardi@athena.polito.it, ferraris@athena.polito.it
}

There are different methods for producing channel planar waveguides in silica based glasses: for example, the Ion Exchange technique [1], the Chemical Vapour Deposition techniques (as PECVD [2], FHD [3]) followed by the RIE (Reactive Ion Etching) and/or UV writing through a photolithographic mask [4], which is commercially developed, and by the direct UV writing of waveguides [5].The advantage of direct UV writing is that there is no need to use photolithography, which involves high cost fabrication steps. In ref [5] direct UV written waveguides were produced using PECVD deposited layers. To date, there has been no reported literature on direct UV written channels on bulk glass. The advantages of bulk glasses are: the ease and low cost procedure of batching the melt, the composition is easily changeable, large amounts of volatile components can be introduced and large quantities of active ions can be incorporated.

The glasses studied are called SGBN from the initials of their main oxide components: silica, germanium,

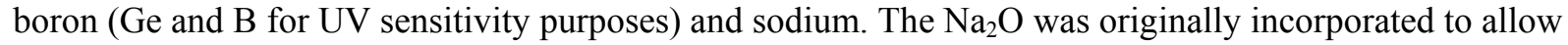
for ion exchange processing [6][7]. In a previous work photosensitivity of both bulk and ion exchanged SGBN glasses has been demonstrated: a high photosensitivity was displayed by the $20 \% \mathrm{~mol} \mathrm{GeO}_{2}$ glasses, with refractive index changes up to $3 \cdot 10^{-2}$ after exposure to a pulse excimer UV laser [8], leading to the conclusion that such glasses could be used for direct UV writing experiments. Two glasses were prepared with concentrations of $\mathrm{GeO}_{2}$ at $6 \%$ and $20 \%$ mol such that the sum of $\mathrm{SiO}_{2}$ and $\mathrm{GeO}_{2}$ is kept constant. They were melted in an electric furnace at appropriate temperatures using Pt crucibles, stirred, cast on a $\mathrm{Cu}$ plate at room temperature and then annealed. This part of the work was performed at the Politecnico di Torino. Thermal analysis were performed in order to measure the glass transition temperatures ( $\mathrm{Tg}$ ) and the expansion coefficient ( $\alpha$, from 40 to $300^{\circ} \mathrm{C}$ ) of the two glasses. As shown in Table 1, there is not a great difference between the two glasses in terms of $\mathrm{Tg}$, but the expansion coefficient of the $20 \%$ glass is higher than the $6 \%$ one. The glasses are stable with no apparent onset of crystallization.

\begin{tabular}{|c|c|c|c|}
\hline Sample name & $\% \mathrm{~mol} \mathrm{GeO} 2$ & $\operatorname{Tg}\left[{ }^{\circ} \mathrm{C}\right]$ & $\alpha \cdot 10^{-7}\left[{ }^{\circ} \mathrm{C}^{-1}\right]$ \\
\hline SGBN 17 & $6 \%$ & 536 & 88 \\
\hline SGBN 20 & $20 \%$ & 532 & 101 \\
\hline
\end{tabular}

Table 1 - Thermal properties of the SGBN glasses

Optical measurements were performed on both glasses. UV absorption measurements of the glasses showed an absorbance peak around $240 \mathrm{~nm}$ with absorption of 57 and $600 \mathrm{~dB} / \mathrm{cm}$ for the $6 \%$ and $20 \%$ 
glasses respectively. The samples, obtained after cutting and polishing the cast glass, were exposed to $244 \mathrm{~nm}$ radiation using an intracavity frequency doubled Ar ion laser. The samples were set on a computer controlled

3D translation stage, and were translated perpendicular to the incident UV laser beam at different laser powers and scan rates. Observations of the samples were made using optical microscopy, alfa step profiling, and by launching light with a He-Ne laser. Numerical aperture evaluations were made with the far field image of the waveguides.

On the $6 \% \mathrm{GeO}_{2}$ the first series of exposures were made at $\mathrm{P}=350 \mathrm{~mW}$ with scan rates ranging from 3000 to $3 \mathrm{~mm} / \mathrm{min}$. Using a scan rate of $3000 \mathrm{~mm} / \mathrm{min}$, the result was a series of ablated channels, which in the alfa step profile appeared as $0.9 \mu \mathrm{m}$ deep valleys with $0.6 \mu \mathrm{m}$ side lobes (an example of an alfa step profile of an ablated channel is shown in Fig.1(a)) . The presence of the side lobes suggest a process involving local melting accompanied by expansion (the glass has a high expansion coefficient) and followed by an ablation. A new series of exposures were performed at lower powers. The most interesting results were obtained at $\mathrm{P}=150 \mathrm{~mW}$, where a series of waveguides were observed: the particular feature was that they were vertical slab waveguides, with width as wide as the beam spot (around $6 \mu \mathrm{m}$ ) extending through the entire thickness of the glass $(0.90 \mathrm{~mm})$ in one direction and following the path of the beam in the other. This result suggests that channel waveguides could be written normal to the surface without scanning the laser beam. A set of exposures were made at different powers, each for a 1 second exposure time. The result showed that at higher power holes were obtained corresponding to ablation, but at medium powers $(\mathrm{P}=100-200 \mathrm{~mW})$ a series of waveguides similar to the core of an optical fibre were evident with a NA of 0.038 , corresponding to a refractive index change of $4.8 \cdot 10^{-4}$. The loss of the waveguides were typically 5.9 and $4.3 \mathrm{~dB} / \mathrm{cm}$ at $633 \mathrm{~nm}$ and $1550 \mathrm{~nm}$ respectively, compared to 5.0 and $4.9 \mathrm{~dB} / \mathrm{cm}$ in the bulk. The higher loss at $633 \mathrm{~nm}$ can in part be attributed to induced loss on UV exposure. UV exposures with an excimer laser at $248 \mathrm{~nm}$ were performed on the bulk glass, and the result was an induced increase of absorption at $633 \mathrm{~nm}$, while at $1550 \mathrm{~nm}$ no change was observed.

The $20 \% \mathrm{~mol} \mathrm{GeO}_{2}$ glass was likewise investigated. The results are shown in Table 2 and compared with the results of the $6 \%$ glass.

\begin{tabular}{|c|c|c|c|}
\hline Power $[\mathbf{m W}]$ & $\mathbf{v}[\mathbf{m m} / \mathbf{m i n}]$ & $\mathbf{6 \%} \mathbf{G e O}_{2}$ & $\mathbf{2 0 \% G e O _ { 2 }}$ \\
\hline 150 & 3000 & slab waveguide & slab waveguide \\
\hline 150 & 300 & slab waveguide & big bump \\
\hline 150 & 30 & slab waveguide & ablated channel \\
\hline 150 & 3 & slab waveguide & - \\
\hline 100 & 3000 & - & slab waveguide \\
\hline 100 & 300 & - & slab waveguide \\
\hline 100 & 30 & - & small bump \\
\hline
\end{tabular}

Table 2 - Results from exposure of the $6 \%$ and $20 \% \mathrm{GeO}_{2}$ glasses.

Three kinds of results were obtained on this glass composition: the slab waveguides, the ablated channels and the bumps. The slab and ablated channels have already been observed in the $6 \%$ glass. Because of the high UV absorption coefficients of the $20 \%$ glass, lower fluencies are needed to write the slab waveguides. The slab waveguides did not go through the thickness of the glass $(1.5 \mathrm{~mm})$ because all the 
light was absorbed in the first few tenth of $\mathrm{mm}$. As with the $6 \%$ glass, a set of perpendicular channel waveguides was attempted without scanning the laser beam, with the power varied from 100 to $10 \mathrm{~mW}$. At $100 \mathrm{~mW}$ the glass was ablated and holes were produced. At intermediate values channels were written and showed an NA equal to 0.06 , corresponding to a refractive index change of $1.2 \cdot 10^{-3}$. The bumps represent the intermediate steps between the a slab and an ablated event. For the glass to melt and expand, as implied here, the glass on UV exposure must have reached a temperature higher than $700^{\circ} \mathrm{C}$. A bump was obtained at $\mathrm{P}=150 \mathrm{~mW}$, characterized by a $0.2 \mu \mathrm{m}$ high and $20 \mu \mathrm{m}$ wide peak (a representative alfa step of a bump is shown in Fig. 1(b)), and with the He Ne laser a spot was produced on the near field image, as shown in Fig.1(c). The spot appeared to be just below the bump toward the bulk glass, and on the bump itself no guiding was detected. Such spot was $20 \mu \mathrm{m}$ diameter and was monomodal. Intensity profile measurements showed a Gaussian profile in both $\mathrm{x}$ and $\mathrm{y}$ directions. The far field image yielded a 0.05 NA value at $\lambda=633 \mathrm{~nm}$, corresponding to a refractive index change of $8 \cdot 10^{-4}$. Loss at $633 \mathrm{~nm}$ is $8.2 \mathrm{~dB} / \mathrm{cm}$, while the bulk glass loss is $2.40 \mathrm{~dB} / \mathrm{cm}$. As for the $6 \%$ glass, UV exposures with excimer laser on the bulk glass showed an increase in absorption at $633 \mathrm{~nm}$.

We have shown that SGBN glasses, which have been designed originally for ion-exchange processing, are suitable also for direct UV writing of channels. There is still much to understand such as the mechanisms responsible for the guiding observed in the presence of the bump. Furthermore, clearly ablation is a limiting feature and one of the things that can be considered is the reduction of the amount of sodium in order to shift the damage threshold to higher fluencies and obtain larger refractive index changes. However, this study does demonstrate the promising prospects that can be exploited like the simultaneous processing of waveguides and gratings, an approach to producing efficient relief gratings and the possibilities for $2 \mathrm{D}$ and $3 \mathrm{D}$ writing inside the bulk glass.

\section{References}

[1] R. V. Ramaswamy and R. Srivastava, J. Lightwave Technol. 6, 984 (1988).

[2] C. V. Poulsen, J. Huebner, T. Rasmussen, L. U. A. Andersen, M. Kristensen, Electron. Lett. 31, 1437 (1995).

[3] G. D. Maxwell, R. Kashyap, B. J. Ainslie, D. L. Williams and J. R. Armitage, Electron. Lett. 28, 2106 (1992).

[4] V. Mizrahi, P. J. Lemaire, T. Erdogan, W. A. Reed and D. J. DiGiovanni, Appl. Phys. Lett. 63, 1727 (1993).

[5] M. Svalgaard, C.V. Poulsen, A. Bjarklev and O. Poulsen, Electron. Lett. 30, 1401 (1994).

[6] M.Ferraris, G.Motta, F.Ortenzio, G.Perrone, D. Pircalaboiu, I.Montrosset, L.Cognolato, Proc. ECIO’97, 334 (1997).

[7] G.Perrone, D.Berger, L.Cognolato, M.Ferraris, G.Motta, D. Pircalaboiu, I.Montrosset, Proc. SPIE, 3282, 31 (1998).

[8] D. Pircalaboiu, D. Milanese, G. Motta, G. Perrone, M. Ferraris, Proc. SPIE 3620, 263 (1999). 
Fig. 2 - 20\% GeO2 glass: (a) alfa step profile of an ablated channel; (b)alfa step profile of a bump; (c) near field image of a bump.
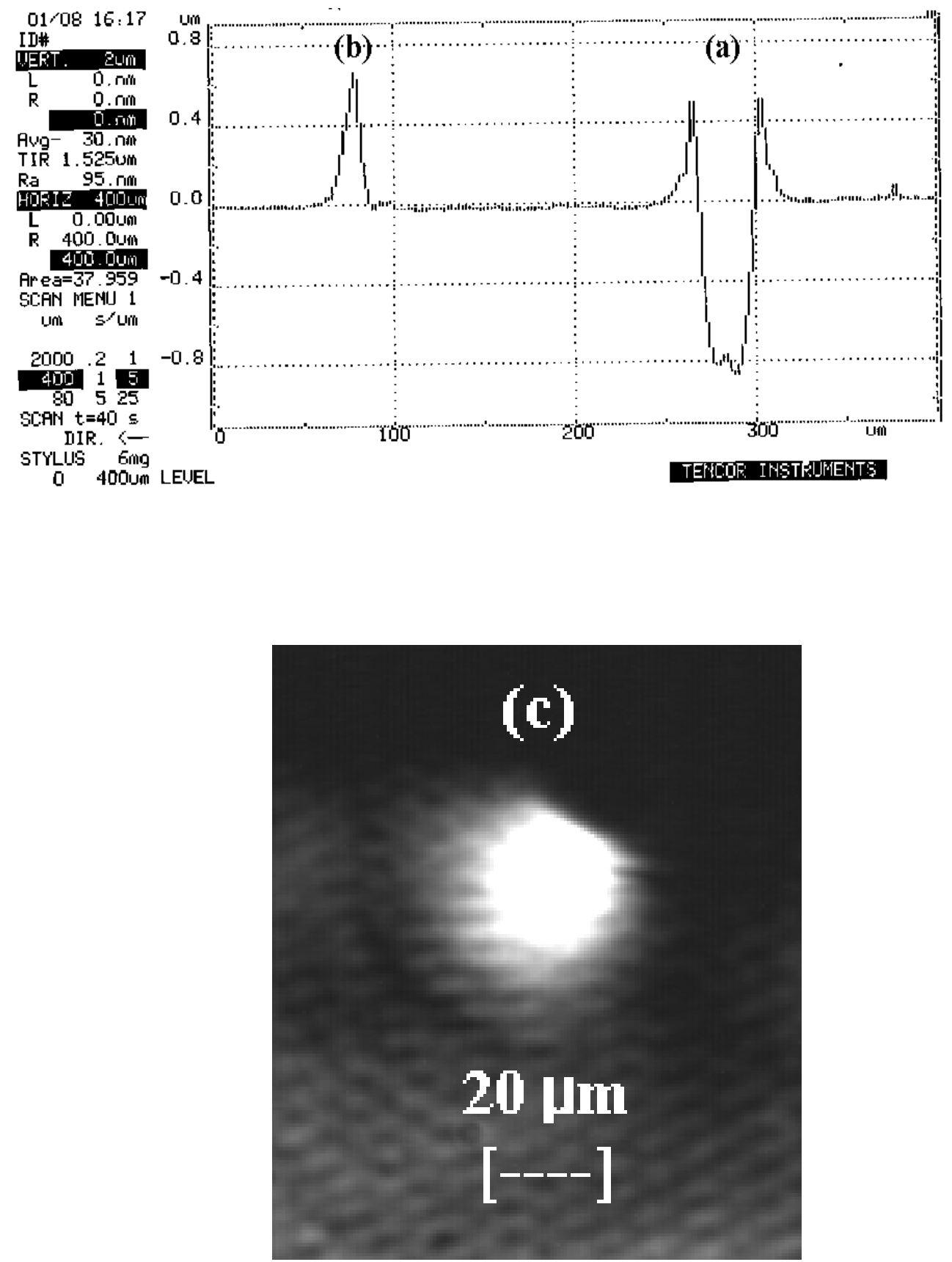
